\title{
The Self- Who Am I?: Children's Identity and Development through Early Childhood Education
}

\section{Doi:10.5901/jesr.2015.v5n1p95}

\author{
Pamela A. Raburu \\ Department of Psychology \& Educational Foundations, School of Education, \\ Jaramogi Oginga Odinga University of Science and Technology, Kenya \\ Email: praburu@jooust.ac.ke/raburu_pamela@hotmail.com
}

\section{Abstract}

\begin{abstract}
Children develop self-identity, who they believe themselves to be, and begin to form relationships through play and peer relations which contribute to their emotional, social and cognitive development. Theories of self generally agree that an early childhood program can foster children's self- esteem and build the foundation for future relationships with others. From interviews and observations, 4 to 6 year olds portray their internal lives of self, construct their personal identity, and how these may affect the learning process. The sample was drawn from 3 pre-school classes in Kenya, consisting of 35 boys and 23 girls $(N=58)$ Sampled expressions of self through children's writings, drawings, dialogues and scaffolding tasks are discussed. The study makes reference to Vygotsky's theoretical framework of social learning theory, highlighting the links between children's learning, play, language, peer relationships and identity. The challenges for early childhood Education and Care are explored while trying to answer questions of identity facing young children such as, 'Who am I?' 'What will I be when I grow up?' Data from children's expressions show that identity differs from one child to another, and that children's self can be modified. The notion of 'identities' rather than an 'identity' emerged. The study indicates that children's selves are shaped by local the environment, values, and each child's unique development.
\end{abstract}

Keywords: identity, self, play, role models, gender

\section{Introduction}

Identity is a legal concept within the UN Convention on the Rights of the Child. It is every child's entitlement from birth.

The child shall be registered immediately after birth and shall have the right from birth to name, the right to acquire a nationality and, as far as possible, the right to know and be cared for by his or her parents

(United Nations, 1989, Article 7.1)

A birth certificate therefore is the most visible evidence of respect for every child's unique identity. The legal identity is established from birth, whereas personal, social and cultural identity grows and changes (Woodhead, 2008). Early childhood educators through research and practice emphasise that a quality early childhood experience for a child has profound effects upon the child's schooling outcomes (Siraj-Blatchford, 2008).

Early childhood is a significant period for the mental functions of children, and the developments include the emerging of the abilities and skills in areas such as language, motor skills, psychosocial and learning. These can be greatly influenced by the nature of the educational environment which the child is exposed in the first years of life (Bowman, Donovan and Burns, 2001).Young children's earliest years are the foundations for their physical and mental health, emotional security, cultural and personal identity, and developing competencies (United Nations Committee on the Rights of the Child, 2005, paragraph 6 (e)).

Another dynamic surrounds 'personal' versus 'social' identity. Personal identity refers to children's subjective feelings about their distinctiveness from others, their sense of uniqueness, of individuality. Social identity refers, on the other hand, to the ways in which they feel they are (or would like to be) the same as others, typically through identification with family and/or peer culture (Schaffer, 2006). Factors like age, gender, religious background, ethnic background, interests, role models and celebrities, talents and hobbies play a part in a child's emerging concept of self. As children develop their identity and perceptions about their self, children's identities, introduces self and family members to others- initiates interaction with others. These selves are shaped by local environment, values and by unique development (Schaffer, 2006, p. 83-85), achieving a positive sense of gender identity'.

Warin (2010) brings to light the questions about identity and argues that self is crucial to a person's overall psychological well- being as it enables one to take control of our lives, and helps to manage our experiences. Young 
children construct personal identity through relationships with others. Woodhead $(2008, p .6)$ highlights that identity has two distinct aspects - "that of the unique individual person and that of the shared social person".

In addition, identity is expressed through children's subjective feelings about themselves and about others. Mell (1991) complements that as children are social actors with personal agency, with awareness of 'self as subject', (or 'l'). a senses of 'self as object' (or 'me') which is more gradually emergent, changing and reflective Identity encompasses 'I' and 'Me'

Warin's (2010) longitudinal study with children from 3 to 17 years notes first; the changeability of self: identity does not exist outside the social context in which it is constructed while the second approach stresses the continuity of self: something that the person carries about with them through time and through the range of social situations they participate in. In Warrin's (2010) study the stories of pre-school children, highlight personal aspects of identity emphasizing the educational importance of self awareness and awareness of others. The importance of peers is emphasized in Dunn (2004) arguing that having friends for children is an important resource for developing identities and that, those children who may be rejected by peers or lack friends may suffer victimization and bullying (Dunn, 2004). Children establish their own identity through comparing themselves with other children and that children starting school (ECE) seem to like school better and adjust if they have found friendship. Friendship is of value to children as they help each other understand the world in which they live. According to Dunn (2004), the quality of children's friendships affects their development of a sense of personal and social identity. Children with friends have better social skills and fewer adjustment problems as friends provide social support and can protect against the difficulties of starting school, victimization and bullying (Dunn, 2004). Having friends is an important resource for developing identities.

Studies (George, 2007; Weller, 2007).have discussed the importance of friendship groups in relation to identity formation As Currie, D., Kelly, D. and Pomeramtz, S. (2007) note, membership of a group (or exclusion from it) can greatly inform the construction of 'who you are' in terms of identity- both in relation to one's own self-identity and how others see you. Children's peer cultures work to influence and constrain the ways in which children construct meanings and values, act and communicate with each other; conduct aspects of identity in relation to themselves and their peers (Adler, P. Kless, S. and Adler, P., 1992)..

Play is crucial in Early Child Education (ECE). and parents, caretakers, preschool teachers play a vital role in the early years of a child's education. (Wood 2004). Children try to gain a sense of self and identity of their own when they associate with other people around them. During the early years of childhood (first 8 years) major development of brain occur and lack of play activity based education can negatively impact on the child's cognitive development as in Piagets (1956), a crucial stage for identity development. Children develop self-identity and begin to form relationships. Play contributes to children's emotional development and since play requires use of multiple motor and mental functions, children develop various skills as well. Play based learning aids children in developing moral and social skills.

Vygotsky's (1978) social learning theory emphasises the social context of learning and the construction of knowledge through social interaction., with an emphasis on collaboration, social interaction and socio-cultural activity (Rogoff, 2003). The main implication of Vygotsky's theory for teaching is that pupils need many opportunities to learn with a teacher and more-skilled peers. Piaget (1956) too argues that play advances children's cognitive development, increases exploration, allowing them to practice their competencies and acquired skills in a relaxed and pleasurable way. For example, children who have just learned to add or multiply begin to play with numbers in different ways as they perfect these operations, laughing as they do so. Erikson (1980) is in agreement that that play is essential for children's health and helps children to master their anxieties, conflicts and increases affiliation with peers.. In addition, Vygotsky (1978) considered play to be an excellent setting for children's cognitive development, especially in the symbolic and make-believe aspects of play, as when a child substitutes a stick for a horse as if it were a horse, uses a piece of paper to make a boat, airplane. For young children, the imaginary situation is real. Parents should encourage such imaginary play, because it advances the child's cognitive development especially creative thought.

Siraj-Blatchford's (2009) research in U.K. shows that teachers are a significant factor in determining concept formation of young children. This work has highlighted 'play-based programmes' and the importance of teachers generating shared and sustained conversations with children (Siraj-Blatchford, 2004). Similarly, Wood (2008) cites that play in education setting has always been strong on ideology but weak, a problematic in practice. Different views on what constitutes play (Siraj-Blatchford; 2009) have been put across different subjects being taught by individual teachers.

Schaffer's (2006) study brings to light that the understanding of the concept of identity has changed, in two aspects. The first is that children acquire a unique and simple identity in their early years, one which remains stable throughout their lives and in different circumstances. The second arises from cross-cultural research, which has shown how identities are acquired or constructed in different ways in different societies, and there is unlikely to be a universal 
model for this process. Young children's identities may be multiple and complex. Brooker $(2008$, p.10) states that changing cultural and social contexts, and new relationships, allow individuals to develop new or modified identities. 'There is therefore a tendency to understand identity as a multiple construct or to describe individuals as acquiring multiples 'identities'.

Developing positive identities touches on some fundamental questions facing every young child: 'who am I?', Is it ok to be who I am? and what is my place in the world? Answering these questions are important to every child's wellbeing, and lack of qualified teachers has been cited in ECE (Siraj-Blatchford, 2009). Siraj-Blatchord (2009, p.156) emphasises that "teachers are a significant factor in determining concept formation and identified among other factors: effective pedagogies have good curriculum knowledge and child development; the most highly qualified staff provide the most direct teachings as well as the kind of interaction that guide children's thinking; less qualified staff are better pedagogies when supervised and supported by qualified teachers".

Holmes and BrownHill (2010 study of pre-school children in the United Kingdom emphasises that there is the lack and the need for male teachers in both ECE and in primary schools to act as role models, for boys as also emphasized in (Hutchings et al., 2008; Parking, 2009;Carrington, B., Francis, B., Hutchings, M., Skelton, C., Read, B. and Hall, I., 2007).

\section{Research Questions}

The following research question formed the basis for the present study:

1. Who would you like to be when you grow up?

2. What are the reasons for the choice of an identity?

3. How are the boys 'and the girls' choices of identity different or similar?

\section{Methodology}

The study employed a descriptive qualitative method through interviews and observations of three pre-school classes of $, 4,5$, and 6 years olds in Kenyan. The class of 4 year-olds had 15 children, 5 year olds were 18 while the 6 year-olds had the largest with 25 children ( $N=58$ ). Consent was sought from parents of the participating pre-school children, by asking them to fill a consent form (see Appendix 1) for ethical considerations according to Creswell (2014)

The interviews were semi-structured and lasted 10 minutes for each child. The interview transcripts/recordings were transcribed and coded transcripts as in Raburu (2011) were analysed using content Analysis and the different themes that emerged were identified (Braun and Clarke, 2006).

In addition, overt observations by the researcher were carried out during normal class sessions and pre-school children were asked to write or draw a picture of what they wanted to be when they grow up.. All participants were asked to draw a picture of what they would like to be when they grow up (see Figures, 1, 2, 3 and 4). The class of 6 year- olds were in addition to drawing asked to write a small paragraph about who they would like to be when they grow up and why. The names used in the study were not the real names of the children so as to protect their identity, thus exercising the ethical principle of anonymity.

\section{Results from Interviews and Observations}

Table 1. Identity of pre-school children

\begin{tabular}{llc}
\hline \multicolumn{1}{c}{ Identity } & \multicolumn{1}{c}{ Gender } & $N$ \\
\hline Teacher & (Girls=6, Boys=5) & 11 \\
Doctor & (Girls=2, Boys=5) & 7 \\
Nurse & (Girls=4, Boys=0) & 4 \\
Driver & (Girls=0 Boys=2) & 2 \\
Pilot & (Girls=1 Boys=2) & 3 \\
Policeman & (Girls=0 Boys=5) & 5 \\
Mum & (Girls=4 Boys=1 & 5 \\
Dad & (Girls=2 Boys=3 & 5 \\
Athlete & (Girls=1 Boys=4) & 5 \\
Footballer & (Girls=0 Boys=6) & 6 \\
Family member & (Girls=2 Boys=1) & 3 \\
(sister, brother, aunt, uncle) & & \\
TV character & (Girls=0 Boys=2) & 2 \\
Religious leader & (Girl=1 Boys=0) & 1 \\
Total & & $\mathbf{5 8}$ \\
\hline
\end{tabular}


The pre-school children were asked a question, "What would you like to be when you grow up?" Reponses from interviews, drawings and writings revealed different identities. As shown in Table1. In support, Sirach-Blatchford's (2009) study in the United Kingdom indicates that teachers are significant for young children's concept formation. How children negotiate identities as teachers- a negotiation that is embedded in the practices including the teaching of young children. It shows how identity positions of 4 to 6 -year- olds are compatible with good learning identities in the classroom (Brookes, 2008). What is the implication of young children's relationships with their teachers in relation to their identity and learning? Children want to associate or identify with their teachers, as they seem to admire the teachers who act as their role models.

While the teachers top in the list of identity, doctors also ranked very highly, reflecting high importance to learning among the young children

\section{Reasons for Choice of Identity}

The second question asked, "What are the reasons for choosing what you want to be when you grow up?" It's interesting to realize the reasons the pre-school children gave for choosing their particular future identity/career. A 5 year old said: "I want to be a doctor like my father, to help the sick'. ' nicely'.

A 4 year old girl replied: My teacher is very kind, funny and makes the whole class laugh, friendly and teaches

Boys' choices for particular fields of life were related to activities such as sports, athletics, being a doctor, a driver and a policeman. When asked why the pupils admired them, their responses included:

A 6 year old boy retorted:: "He is famous has a nice Hammer car, he is strong, brave, got a gold medal, has a lot of money, the doctor has a nice house'

A 5 year old girl: "my mum cooks very nice food" I like my aunt who is a nurse"

Another noticeable significant factor from the study was that pupils' choice of identity was based on their surrounding environment, showing identity as contextualized. Most choices for the people the pupils admired were based on the local Kenyan context (or example, the footballers and athletes). One of the boys however, said that he admired Arsenal (UK football players) team. When asked why, he said he watched them play very nicely on the television and his older brother too supported the team.

The data revealed that some children expressed identities rather than an identity: '...my name is Tanya, I am 4 years old, I am a girl, I like to run'., showing that young children learn gender identity at early ages ( Paechter and Clark, 2007). One of the boys also said that he would like to be a footballer and a teacher. Similarly. Brooks (2003) expresses that young children's identities may be multiple and complex and that the changing and social context and new relationships allow individuals to develop new or modified identities.

\section{Gender and Identity}

The third research question asked, "How are the boys 'and the girls' choice of identity different or similar? "

In making choices for being a teacher, gender options was lacking for boys as all the teachers were female in the 3 classes. Holmes and BrownHills (2010) study in U.K. of pre-school children emphasizes the lack of and the need for male role models in Early Childhood Education .In addition to eight girls choosing teaching, others chose nursing, admiring their mothers and two admired their aunts who are nurses and a TV character respectively. The girls choice of mums and aunts could be alluded to cultural effects as expressed in (Brooks, 2003).

Gender differences was noticeable, in choices of "footballer", "driver", "athletes, "driver" and "pilot"'by boys only, while "mum' "nurse", aunts, were from girls only. This shows that gender differences in terms of roles and choices of identity may begin emerging at early stages of children's development (Paechter and Clark, 2007). Gender identity could be attributed to family socialisation cultural impact, the media effects, and role models. Daltsman's (2009) study of preschool children's dictate and dramatizes stories in the classrooms."Children have ascribed gender stereotypes by the time they are two years old because the clothing and toys a baby is given are chosen by adults, with an eye toward gender" (Hitz and Hewes 2011, pg 25-26). The process of children telling stories can be a medium of gender identity., assigning roles in stories and drama characters. 


\section{Observation Tasks}

Children participants were asked to perform tasks during normal class sessions as the researcher and the teacher watched. Those who could not spell the names of what they want to be were asked if they could then draw a picture instead. Commonly, some of the 5 and 6 year olds were able to write who they wanted to be, while 4-years-olds drew pictures, thus expressing their identities through drawings.

Figure 1: A 4 year old has drawn a ball to show her admiration of a footballer. She writes English (ball) and Kiswahili (mipira).

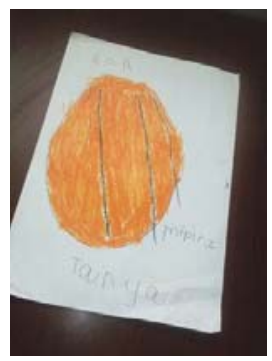

Figure 2: A picture of an airplane drawn by a 6 year old to represent a pilot.

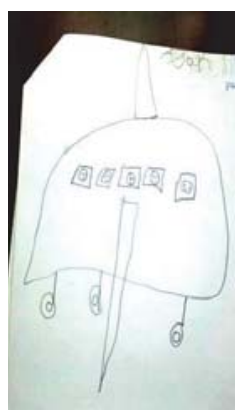

Drawing dialogues from Figure 1 and Figure 2 allow children to move from spontaneous concepts to more scientific concepts and play an important role in promoting higher mental functions. Piaget (1956) argues that a child's drawing performance reflected the child's cognitive competence. When we consider drawing to be a mediation tool and a language, it engages the child's past, present experiences, imagination and observation (Brooks, 2003). Brooks (2003) further emphasizes that young children's identities may be multiple and complex and that, changing cultural and social context and new relationships allow individuals to develop new or modified identities.

Figure 3: Drawing by a 4 year old girl

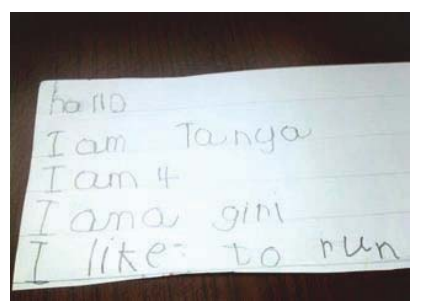

The drawing by a 4-year old girl shown in Figure 4 expresses different identities: name, age, gender and an athlete (run).

The present study suggests that when drawing is used in a collaborative and communicative manner, it becomes a 
powerful meaning-making tool, supporting higher mental functions, as shown in (Siraj-Blatchford, 2009). This was evident from the children's drawings of: police cars to represent a police officer, airplanes to represent a pilot, balls to represent a footballer, people running to represent athletes. When children draw, they become fully engaged with the subject being drawn, involving memory, and thus, emergent thinking.

According to Warin (2010), the children's stories told in her book confirm Erikson's (1980) linkage of identity and wellbeing, which concludes that 'a sense of self is a resource for coping and managing our social experiences.

Figure 4: Pictures of police cars represent the child's (5 year-old) identity of wanting to become a police officer.

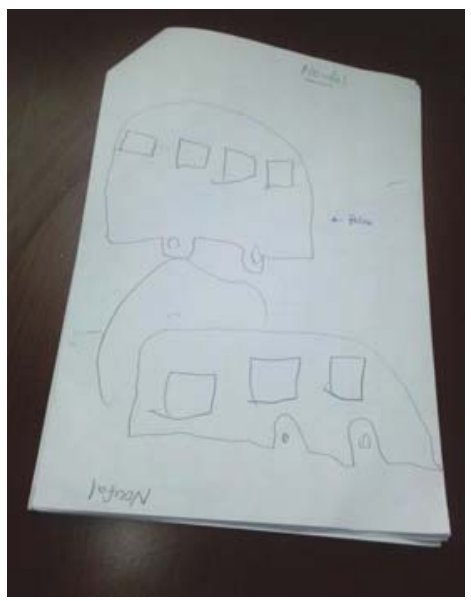

Brooks (2003) states that drawing is a unique mental tool for young children through which they form interpersonal and intrapersonal dialogue.

\section{Conclusions}

The paper explores the links between who young children want to be when they grow up and the reasons for their choices. While the search for identities continue in early childhood stage, this paper highlighted the importance of friendship, peers and play in the formation of identities among young learners. The pupils expressed their feeling of who they really are, who they want to be through different tasks in drawing, and scaffolding tasks in addition to the interview questions asked.

From the study, Warin (2010) found that much of children's identity depended on the opportunities they had both in school and out of school for reflecting on their social relationships, making social comparisons and building up a narrative self. Gender identity was conspicuous from the present study as girls identified with female characters and certain jobs regarded as feminine- like a mum, nurse, female teachers. A similar study by Read (2011) showed how teenage girls identified with female singers as their role models, with majority citing, Beyonce and Britney. Boys in the present study on the other hand, chose careers such as driver, policeman, pilot, doctor and admired athletes and footballers. There was no distinct gender difference in choice of teaching as a profession or admiring their teachers. The boys had no gender choices as all the teachers were female- this raises the question of the continuing lack of male teachers in ECE which is a challenge. Carrington et al., (2007) call for male teachers to be recruited to teach in ECE and primary schools in order to act as role models for male pupils. Similarly, Holmes and BrownHill's (2010) critical discussion focus on male absence in the early years.

Significant too to the findings was the influence of the social context: the use of Kenyan national language, Kiswahili. Although English is the official medium of communication in Kenyan schools, young children expressed themselves with ease in Kiswahili as they mentioned and drew who they wanted to be when they grow up. There was also a tendency to mention famous Kenyan footballers and athletes. Rather than making a choice of one identity, the majority of the pupils expressed identities (name, age, gender, and what they would like to be when they grow up). 


\section{Recommendations}

1. It is essential that policy addresses the issue of how pre-school children develop their identity at an early stage and how that could be incorporated in the teaching.

2. Teachers are role models and are key players in pre- school's children's cognitive and social development, of which the process of identity formation is part.

3. The Kenyan government should encourage ECDE training opportunities for male teachers so that the male students would have role models, a key part of identity formation

4. Young children should be encouraged to have friends/peers which is essential for identity formation.

5. Through play, pre-school children form their identities thus, teachers should incorporate play in teaching and learning processes.

\section{References}

Adler, P., Kless, S., and Adler, P. (1992). Socialization to gender roles: Popularity among Elementary School boys and girls. Sociology of Education, 65, 169-187.

Bowman, B. Donovan, M., and Burns, M. (2001). Eager to Learn: Educating Our Preschoolers, Committee on Early Childhood Pedagogy, Commission ob Behavioral and Social Sciences and Education, National Research Council, National Academy Press, Washington, DC.

Braun, V. and Clarke, V. (2006) Using thematic analysis in Psychology. Qualitative Research, 3, 77-101.

Brooks, M. (2003). Drawing as a unique mental development tool for young children: Interpersonal and intrapersonal dialogues. Contemporary Issues in Early Childhood, 6, 80-91.

Carrington, B., Francis, B., Hutchings, M., Skelton, C., Read, B. and Hall, I. (2007). Does the gender of the teacher really matter? Seven-to-eight- year-olds' accounts of their interactions with their teachers. Educational Studies, 33, 397-413

Creswell, J.W. (2014) Research Design, Qualitative, Quantitative and Mixed Method Approaches. Los Angel: CA. Sage publication.

Currie, D., Kelly, D., and Pomerantz, S. (2007). 'The power to squash people': Understanding girls' relational aggression. British Journal of Sociology of education, 28, 23-37.

Daltsman, J. (2009) "Once Upon a time there was...Forms and functions of story dictation in pre-schools. In here the story ; Using narratives to promote young children's language and literacy learning ed. D.R. Meier. New York Teachers College press.

Dunn, J. (2004). Children's Friendships. The beginnings of intimacy. Malden, MA, Blackwell.

Erikson, E. H. (1980). Identity and the Life Cycle. New York: Norton.

George, R. (2007). Girls in a goldfish bowl: Moral regulation, ritual and the use of power amongst inner city girls. Rotterdam: Sense.

George, R. and Brown, N. (2000). 'Are you in or are you out? An exploration of girl friendship groups in the primary phase of schooling. International Journal of inclusive Education, 4, 289-300.

Hitz B.F. and Hewes, D.W. (2011) Practical applications from the history of gender and early childhood . In T. Jacobson Perspectives in gender in early childhood. St. Paul MN Redleaf.

Holmes, G. R. and BrownHills, S. (2010). Where are the men? In L. Miller and C. Cable, (eds) Professionalization, Leadership and management in the Early Years. London: Sage.

Hutchings, M. Carrington, B., Francis, B., Read, B. , Skelton, C. and Hall, I. (2008). Nice and kind, smart and funny: What children like and want to emulate in their teachers. Oxford Review of Education, 34, 135-57.

Miell, D. (1990). 'The self and the social world' in Roth, I. (ed.) Introduction to Psychology, Volume 1. London, Erlbaum.

Paechter, C. and Clark, S. (2007). Learning gender in primary school playgrounds: Findings from the tomboy identities study. Pedagogy, Culture and Society, 15, 317-331.

Parkin, P. (2009). Need for more male role models. Early Years Educator, 10, 6.

Piaget, J. (1956). The child's conception of space. New York; Macmillan.

Raburu, P.A. (2011) Women Academics' Careers in Kenya. PhD Thesis. Lancaster University. United Kingdom.

Read, B. (2011). Britney, Beyonce and me- primary school girls role models and construction of the "popular girl". Gender and Education, 23, 1-13.

Rogoff, B. (1990). Apprenticeship in thinking: Cognitive development in a social context. Oxford. Oxford University press.

Schaffer, H.R. (2006). Key Concepts in Developmental Psychology. London. Sage.

Siraj-Blatchford, I. (2009). 'Conceptualising progression in the pedagogy of play as sustained shared thinking in early childhood education: a Vygotskian perspective', Educational and Child Psychology, 26, (2).

Siraj-Blatchford, I. (2004). Quality teaching in the early years. In A. Anning, J. Cullen, and M. Fleer (eds) Early Childhood education: Society and Culture. London: Sage Publication.

Siraj-Blatchford, I. (2008). Understanding the relationship between curriculum, pedagogy and progression in learning in early childhood', Hong Kong Journal of Early Childhood Education, 7, (2), 3-13.

United Nations (1989). Convention on the Rights of the Child. Un General Assembly Document a/RES/44/2. New York, NY, United Nations. 
United Nations Committee on the Rights of the Child (2005). Implementing Child Rights in Early Childhood, General Comment No. 7 , Geneva, United Nations; also available on line at: www.ohchr.org/english/bodies/crc/docs/advanceVersions/GeneralComment7 Rev1.pdf(Accessed June 2007).

Vygotsky, L. (1978). Mind in Society: The development of higher psychological processes. Cambridge, MA, Cambridge University Press. Warin, J. (2010). Stories of Self: tracking children's identity and wellbeing through school years. UK: Trentham Books

Weller, S. (2007). 'Sticking with your mates?' Children's friendship trajectories during the transition from primary to secondary school. Children and Society, 21, 339-351.

Wood, E. (2004). Developing a pedagogy of play. In Anning, C., Cullen, J., and Fleer, M. (eds) Early Childhood Education: Society and Culture. London. Sage Publication.

Woodhead, M. (2008). Legal identity is conferred by birth registration. In Brooker, L. and Woodhead, M. Developing Positive Identities: Early Childhood Focus 3: Milton Keynes, U.K.: Open University Press.

\section{Appendix 1}

\section{Parent's Consent Form}

I am carrying out a study which is to try to understand how young children (4-6 years) learn and form their identity, an important aspect of child development.

I wish to request for your permission to allow your son/daughter to participate in this study which will take place during normal classes. The children will be asked simple questions about what they want to be when they grow up, and to draw and write.

- I will ensure confidentiality and that the information they give will only be used for education purposes and in cases where the student's work is published, names will be changed(not real names)

Kindly fill and return the form to your child's teacher to hand over to:

I AGREE/DO NOT AGREE that my child should take part in the study.

The Child's name-

Parent's signature:

Date: 